Fixed Point Theory, 22(2021), No. 1, 169-188

DOI: $10.24193 /$ fpt-ro.2021.1.12

http://www.math.ubbcluj.ro/ nodeacj/sfptcj.html

\title{
REGULARIZED PROJECTION METHOD OF SOLVING SPLIT SYSTEM OF FIXED POINT SET CONSTRAINT EQUILIBRIUM PROBLEMS IN REAL HILBERT SPACE
}

\author{
ANTENEH GETACHEW GEBRIE* AND RABIAN WANGKEEREE** \\ * Department of Mathematics, Faculty of Science, Naresuan University, \\ Phitsanulok 65000, Thailand \\ E-mail: antgetm@gmail.com \\ ${ }^{* *}$ Research Center for Academic Excellence in Mathematics, \\ Naresuan University, Phitsanulok 65000, Thailand \\ E-mail: rabianw@nu.ac.th
}

\begin{abstract}
In this paper, we propose two algorithms which combines Mann iterative scheme, regularization technique and projection method for solving finite family of split equilibrium problems and split common fixed point problems: we call the problems split system of fixed point set constraint equilibrium problems (SSFPSCEPs). The weak and strong convergence theorems for iterative sequences generated by the algorithms are established under widely used assumptions for equilibrium bifunctions. To obtain the strong convergence, we combine the first algorithm with the shrinking projection method in the second algorithm. Finally, an application and one numerical experiment is given to demonstrate the efficiency of our algorithms.

Key Words and Phrases: Common fixed point problem, split equilibrium problem, monotone bifunction, regularization technique, shrinking projection.
\end{abstract}

2020 Mathematics Subject Classification: 90C25, 68W10, 47H10, 47J25.

\section{REFERENCES}

[1] Y. Censor, T. Elving, A multiprojections algorithm using Bregman projections in a product spaces, Numer. Algor., 8(1994), 221-239.

[2] Y. Censor, A. Gibali, S. Reich, Algorithms for the split variational inequality problem, Numer. Algor., 59(2012), 301-323.

[3] P.L. Combettes, S.A. Hirstoaga, Equilibrium programming in Hilbert spaces, J. Nonlinear Convex Anal., 1(2005), 117-136.

[4] J. Contreras, M. Klusch, J.B. Krawczyk, Numerical solutions to nash-cournot equilibria in coupled constraint electricity markets, IEEE Trans. Power Syst., 19(2004), 195-206.

[5] J. Deepho, J. Martinez-Moreno, P. Kumam, A viscosity of Cesaro mean approximation method for split generalized equilibrium, variational inequality and fixed point problems, J. Nonlinear Sci. Appl., 4(2016).

[6] J. Deepho, P. Thounthong, P. Kumam, S. Phiangsungnoen, A new general iterative scheme for split variational inclusion and fixed point problems of $k$-strict pseudo-contraction mappings with convergence analysis, J. Comput. Appl. Math., 318(2017), 293-306. 
[7] F. Deutsch, Minimizing certain convex functions over the intersection of the fixed point sets of nonexpansive mappings, Numer. Funct. Anal. Optim., 1(1998), 33-56.

[8] A.G. Gebrie, R. Wangkeeree, Hybrid projected subgradient-proximal algorithms for solving split equilibrium problems and split common fixed point problems of nonexpansive mappings in Hilbert spaces, Fixed Point Theory Appl., 1(2018), 5.

[9] K. Goebel, A. Kirk, Topics in Metric Fixed Point Theory, Cambridge Studies in Advanced Mathematics, 28, Cambridge University Press, Cambridge, 1990.

[10] Z. He, The split equilibrium problem and its convergence algorithms, J. Ineq. Appl., 1(2012), 162 .

[11] D.V. Hieua, Parallel extragradient-proximal methods for split equilibrium problems, Math. Model. Anal., 4(2016), 478-501.

[12] K.R. Kazmi, S.H. Rizvi, Iterative approximation of a common solution of a split equilibrium problem, a variational inequality problem and a fixed point problem, J. Egyptian Math. Society, $\mathbf{1}(2013), 44-51$.

[13] F. Ky, A minimax inequality and applications, Inequalities, 3(1972), 103-113.

[14] W.R. Mann, Mean value methods in iteration, Proc. Amer. Math. Soc., 3(1953), 506-510.

[15] A. Moudafi, Split monotone variational inclusions, J. Optim. Theory Appl., 2(2011), 275-283.

[16] K. Nakajo, W. Takahashi, Strong convergence theorems for nonexpansive mappings and nonexpansive semigroups, J. Math. Anal. Appl., 2(2003), 372-379.

[17] T.D. Quoc, P.N. Anh, L.D. Muu, Dual extragradient algorithms extended to equilibrium problems, Global Optim., 52(2012), 139-159.

[18] W. Takahashi, Y. Takeuchi, R. Kubota, Strong convergence theorems by hybrid methods for families of nonexpansive mappings in Hilbert spaces, J. Math. Anal. Appl., 1(2008), 276-286.

[19] B. Van Dinh, D.X. Son, T.V. Anh, Extragradient algorithms for split equilibrium problem and nonexpansive mapping, arXiv preprint arXiv:1508.04914. (2015).

[20] B. Van Dinh, D.X. Son, L. Jiao, Linesearch algorithms for split equilibrium problems and nonexpansive mappings, Fixed Point Theory Appl., 1(2016), 27.

[21] D. Van Hieu, Two hybrid algorithms for solving split equilibrium problems, International Journal of Computer Mathematics, 3(2018), 561-583.

[22] T. Zang, Y. Xiang, J. Yang, The tripartite game model for electricity pricing in consideration of the power quality, Energies, 10(2017), 2025.

Received: October 11, 2018; Accepted: June 4, 2019. 